\title{
The First Steps to Develop a Monitoring-Based Method to Support the Sustainable Mosquito Control in an Urban Environment in Hungary
}

\author{
Tibor Kiss ${ }^{1,2, *}$, Csaba Leitol ${ }^{1,2}$, Gergely Márovics ${ }^{1,3}$, Tímea Zentai ${ }^{1,4}$, Roland Baczur ${ }^{1,5}$ (D) \\ and János Girán 1,3 \\ 1 Smart City Technologies Research Group, Faculty of Engineering and Information Technology, \\ University of Pécs, Boszorkány u. 2, 7624 Pécs, Hungary; leitol.csaba@mik.pte.hu (C.L.); \\ gergely.marovics@aok.pte.hu (G.M.); zentai.timea@biokom.hu (T.Z.); baczur.roland@ktk.pte.hu (R.B.); \\ janos.giran@aok.pte.hu (J.G.) \\ 2 Department of Environmental Engineering, Faculty of Engineering and Information Technology, \\ University of Pécs, Boszorkány u. 2, 7624 Pécs, Hungary \\ 3 Department of Public Health, Medical School, University of Pécs, Szigeti u. 12, 7624 Pécs, Hungary \\ 4 Biokom Urban Management Nonprofit Ltd., Siklósi u. 52, 7632 Pécs, Hungary \\ 5 Doctoral School in Regional Policy and Economics, Faculty of Business and Economics, University of Pécs, \\ Rákóczi u. 80, 7622 Pécs, Hungary \\ * Correspondence: kiss.tibor@mik.pte.hu
}

Received: 19 May 2020; Accepted: 17 June 2020; Published: 19 June 2020

check for updates

\begin{abstract}
In Europe, several exotic Aedes species, such as Aedes albopictus, Aedes eagypti, Aedes japonicas and Aedes koreicus, have become established. Mosquito-borne infection has also become a rising public health issue in Europe. This study aims to present the results of the first Hungarian systematic mosquito monitoring (SMM) operating in an urban environment in the city of Pécs. It also explains the implementation of a targeted mosquito control by the development of a mosquito map with the SMM approach, thus contributing to a reduction of the risks of mosquito-borne diseases. The mosquito trapping started in 2015, and the traps were Center for Disease Control (CDC) equipment. Based on the data of the SMM, an urban mosquito data set was developed. It consisted of the data of 441 trappings, and the data were statistically analyzed. The results show that three influencing factors impacted mosquito population: distance from running water, built-up density and average temperature had a causal impact on the average number of mosquitoes of an urban area. Each of these factors showed direct impact, and the impact intensified with the combination of the three factors. On that basis, it was made clear which areas of the city mosquito control activity should be focused. Areas of the city where interventions of lower intensity may be necessary compared to the intensity of the earlier mosquito control measures could also be determined. Compared to the previous practice, in which the entire city was involved in intensive mosquito control, now the intensive larviciding is advised to be applied in $42.1 \%$ of the total residential areas of the city. Thus, mosquito control of lower intensity could also be sufficient in the remaining $57.9 \%$ of the city area. This resource reallocation based on planning can boost the efficiency of the control and lead to a positive change towards sustainability regarding reduced pressure on the environment and reduced expenses of protection.
\end{abstract}

Keywords: data analysis; GIS; multi-sectoral approach; urban health; urban management; strategic planning 


\section{Background}

The majority of people now live in urban areas and will do so for the foreseeable future [1]. At the same time, urban lifestyle increases the risk of chronic diseases [2], lifestyle-related health concerns [3] as well as the risk of infectious diseases [4]. Health risks caused by the impact of climate change appear to be a new threat especially affecting those living in an urban environment [5]. Accordingly, the desire to create an urban environment ensuring healthy and safe living conditions is becoming even more pressing both at the local and global level. The importance of this task is underlined among others by the objectives of Goal 3 (SDG Goal 3: Ensure healthy lives and promote well-being for all at all ages) and Goal 11 (SDG Goal 11: Make cities and human settlements inclusive, safe, resilient and sustainable) of the Sustainable Development Goals 2030, which encourage the creation of a healthy and resilient urban environment and the protection of the health of people living in the cities [6].

Special attention should be paid to infectious diseases among the health risks of the urban environment. The large number of inhabitants and high population density of cities, the significant volume of interpersonal interactions and the large-scale coverage of built-up areas can contribute to the rapid spread of diseases interacting with each other $[7,8]$. Such circumstances are ideal for the spread of vector-borne diseases because competent vectors can easily transmit pathogens from one person to another person [9]. Not surprisingly, nearly $80 \%$ of humanity is exposed to the risk of vector-borne diseases. The extent of human exposure is well indicated by the fact that $17 \%$ of the global burden of diseases is caused by infectious diseases, and more than 700,000 deaths per year are linked to vector-borne diseases [10].

Furthermore, there is increasing evidence that the average temperature rise caused by climate change and also the change in the amount and distribution of precipitation in the European region can lead to the establishment of several invasive mosquito species that can transmit new diseases or diseases already regarded as eliminated [11]. An additional risk arises from the fact that the local mosquito stocks can also become competent in transmitting the new pathogens; thus, the epidemic-like spread of diseases previously not typical in the given area may cause a real hazard [12]. It is extremely difficult to anticipate the risks that the mediation of the vectors can pose regarding the known and newly emerging diseases. New diseases are expected to appear from time to time. Recent events, with the emergence of the COVID-19 pandemic, have also proven this notion. There is a reason to expect that the Aedes mosquitoes may have a role in the transmission of pathogens of newly emerging diseases. As regards the preventive tasks, all measures can contribute to the solution to the problem that would decrease risks by targeted measures to reduce diseases caused by mosquitoes and other vectors [13].

In order to reduce the risks of the mosquito-borne diseases and the possible epidemics caused, it is an absolute priority to establish efficient monitoring and surveillance systems and to apply sustainable mosquito control solutions globally [13]. In Europe, a number of exotic species, such as Aedes albopictus, Aedes eagypti, Aedes japonicus and Aedes koreicus have become established. These species have a high vectorial capacity for chikungunya, dengue and yellow fever viruses and more than twenty other arboviruses. The mosquito-borne West Nile virus infections of humans are currently one of the major public health concerns in Europe. Thus, the public health importance of mosquitoes in Europe is on the rise as well [14]. Nevertheless, according to the resolution of the Hungarian Academy of Sciences published in 2018, a comprehensive state-level mosquito monitoring and surveillance system in Hungary has not been established yet [15].

\section{Introduction}

In Hungary, the first data related to mosquito monitoring activities were recorded in the 1870s. At that time, the species of Culex pipiens was studied. Subsequently, the detailed country-wide mapping of the different mosquito species took place from time to time until the 2010s [16]. Systematic mosquito monitoring (SMM) operated only in the period of 2013-2014, targeted at the Lake Balaton region and concentrating on the invasive species transmitting the pathogens of the West Nile virus [17]. On the 
other hand, Pécs, the fourth largest city of Hungary (with 143,000 inhabitants) was the first municipality in the country to have SMM in an urban environment, which was applied to the whole territory of the city in 2015.

The main objective of SMM in Pécs is to support the planning and implementation of sustainable mosquito control activities in the city. A relevant objective of the SMM is to contribute to the assessment of epidemiological risk and the following risk mitigation. It also supports the establishment of the measurement of effectiveness and efficiency of the mosquito control activities based on the collected data. As a start, a joint operation was established among Biokom Nonprofit Ltd. as the local service provider of urban management; the Virological Research Group; Szentágothai Research Centre of Pécs, a part of the University of Pécs (UP) and the Smart City Technologies Research Group of UP. Biokom Nonprofit Ltd is owned by the municipality of Pécs, whose tasks include, among others, the maintenance of the city's public premises, roads and green areas, as well as the performance of the tasks of local extermination of pests and mosquito control. The Department of Public Health of the Medical School of UP joined the working group in 2018.

The benefits of SMM were apparent by the second year; during the period of mosquito trapping, mosquitoes of the A. koreicus species were captured in the area of the city [18]. A. koreicus mosquito is an invasive species that can potentially be competent in spreading the diseases Dirofilaria immitis, Dirofilaria repens, Brugia malayi, Japanese encephalitis virus and chikungunya virus [19]. Since the first observation in Pécs, it has been confirmed that the species of $A$. koreicus has established in the southern part of Hungary, where Pécs is situated [20].

The establishment of $A$. koreicus within the city is a good example to show that the widespread mosquito control strategy in Hungary focusing on adulticiding of imagoes is far less suitable than the strategy focusing on larviciding [12]. For the adulticiding of imagoes, aerial spraying used to be the most widespread solution to mosquito control in Hungary for a long period of time. However, this method has only a short term effect, and it has a low level of effectiveness [21]. A further problem is that this control strategy is based on the aerial spraying of waste areas. Thereby, the used chemicals can cause several negative spill-over effects. These can include the mortality of bees, other pollinating insects and aquatic life as well as the additional environmental impact caused by the carrier dispensed together with the toxicant [22]. Moreover, this procedure can even pose a risk to human health in the absence of a targeted application of toxins. Accordingly, the usage of biocidal products was banned by the Chief Public Health Officer of Hungary in 2019. The regulations of the Chief Public Health Officer concerning the ban on the use of biocidal products were laid down alongside the Directive 98/8/EC of the European Parliament and of the Council as well as the Regulation 528/2012/EU of the European Parliament and Council concerning the marketing and use of biocidal products. The transition to mosquito control based on non-chemical processes preferred in other European countries has therefore been necessary. Since these solutions focus mainly on larviciding, their effective application presupposes the precise delimitation of their breeding areas [12].

The aim of this study is to present the results of a systematic mosquito monitoring (SMM) activity in urban environment during a five-year period. The initial assumption was that different natural and built environmental characteristics of the urban area may have different mosquito densities between different parts of the city. Consequently, a mosquito map can be developed if the study detects different mosquito densities between the different parts of the city. It was also expected that with the help of the mosquito map, the identification of urban areas for mosquito control may become data-driven for city management.

This study also explains the possibilities to impact city management measures in connection with targeted biological mosquito control and reduction of the risks of mosquito-borne diseases. Finally, we would like to demonstrate methods of targeted involvement of the residents in the mosquito control tasks and to raise public awareness in connection with mosquito-borne diseases, utilizing the results of the SMM activity. 


\section{Materials and Methods}

An urban mosquito data set was developed in the city of Pécs with the aim of supporting information-based mosquito control. The structured data were provided by the mosquito samples captured in the SMM mosquito traps. Eight mosquito traps were placed out in the residential area of the city in 2015. An additional mosquito trap was also installed as a control site in a marshland area outside the residential area. As a result of the continuous development of SMM, the number of the sampling places outside the control site rose to 10 by 2019, and some of the locations were changed. Figure 1 shows the exact place of the sampling spots and also the changes.

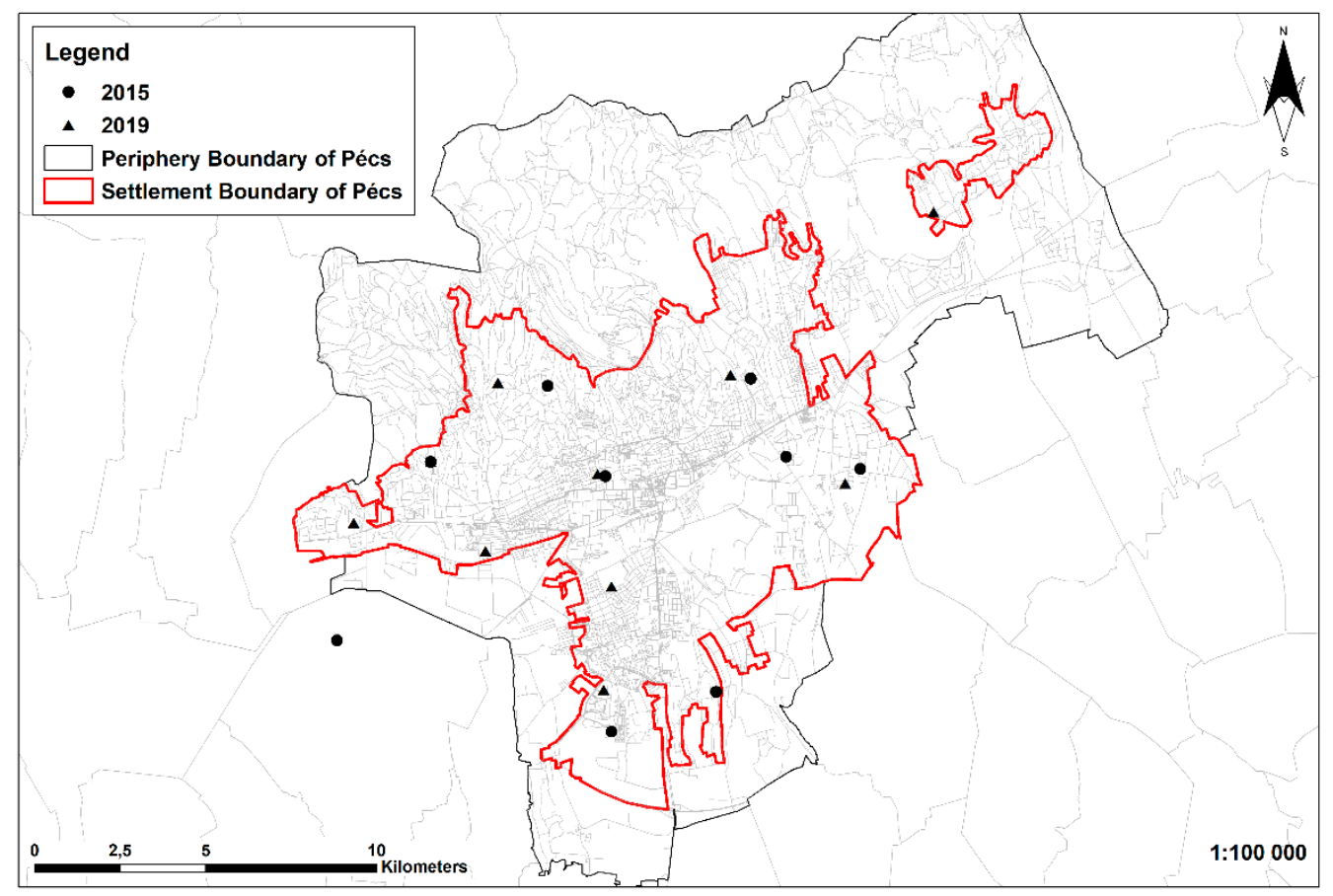

Figure 1. The sites of mosquito trapping in Pécs, 2015-2019.

For the selection of the sampling spots, the built-up density characteristics of the city were taken into consideration. The main principle for the selection of the sampling spots was to cover all the varieties of the built-up density types of the city. The information on the land cover was taken from the free geographical information data set of Corine Land Cover 2018 of the Copernicus system to characterize the built environment. Information on the built-up density of the urban areas was also found in the free geographical information data set of Urban Atlas 2012 of the Copernicus system. These sources have been utilized earlier in several research projects where the land cover-related data were relevant [23-26]. Finally, traps were placed the following parts of the city: arable land (annual crops); continuous urban fabric (sealing layer (S.L.): $>80 \%$ ); discontinuous medium density urban fabric (S.L.: 30-80\%); discontinuous very low density urban fabric (S.L.: $<30 \%$ ); forests; green urban areas; industrial, commercial, public, military and private units and pastures. The following parts of the city were not covered by traps: construction sites; fast transit roads and associated land; isolated structures; land without current use; mineral extraction and dumpsites; other roads and associated land; permanent crops (vineyards, fruit trees, olive groves); railways and associated land. Finally, we must highlight that, since the built-up density of the urban areas was not evenly distributed within the city, the trap distribution was adapted to match the selected parameters, and the traps were not distributed evenly.

Trappings started in May each year during the period of the study and finished at the end of September. The traps were developed by the Center for Disease Control and Prevention (CDC) and used light and dry ice $\left(\mathrm{CO}_{2}\right)$ for attraction. The traps operated from 6 p.m. every Wednesday to 6 a.m. 
on Thursday. In 2016, having captured the first A. koreikus specimen with the traps, more mosquito capture took place using the method of human landing at randomly chosen locations of the city, in order to confirm the presence of $A$. koreikus in the city through applying a different methodology to trapping. The counting and faunistic analysis of the individuals captured during the trapping periods was continuously done by the experts of the Virological Research Group.

The data set to detect the characteristics of the mosquito situation in the city was based on the geographical coordinates of the trapping sites and also on the number and faunistic features of the trapped mosquitoes. The data were also supplemented by data referring to the land cover of Pécs, the gradient conditions of the ground, the built-up density of the area as well as the location of running waters and standing waters. To the study of the relationship between mosquito numbers and meteorological conditions, the data of daily average, minimum and maximum temperature, daily temperature range, daily dew-point and daily amount of precipitation during the period under examination were also recorded in the data set.

The geographical information data set of watercourses and water bodies was taken from the free data set of OpenStreetMap. The source of the meteorological data was the official meteorological station of Pécs-Pogány and the meteorological station operated by the Faculty of Science of UP.

The data set included the number and faunistic data of the mosquitoes captured at each site per day, the characteristics of the city ground surface as well as the meteorological features, and it contained the data of altogether 707 trappings. The extreme outliers of captures in the control area and the trapping data containing null values were excluded from the data set. All these gave the basis of the data set of this analysis holding the data records of 441 trappings of the traps placed at different sites of the city of Pécs within the period of 2015 to 2019.

At the beginning of the research, the utilization of an interpolation technique was considered. We had already used the inverse distance weighting (IDW) technique. However, this method was later rejected for the following reasons:

- Seasonality: the number of trapped mosquitoes due to meteorological parameters showed a dynamic change not only annually but also weekly;

- Impacts of modifiers: e.g., built-up density or distance from stagnant waters, which have a positive effect on mosquito numbers. If we omit these factors from our estimate, our prediction will be inaccurate.

The output of this IDW interpolation technique is available as Supplementary Material (Figure S5).

When analyzing the data set with statistical methods, the relationship between the environmental and other impacts and the average number of mosquitoes was examined separately for each variable. In the analysis, the dependent variable was the variable containing the number of the trapped mosquitoes. The selection of the exploratory variables was conducted from the variables of the data set using a forward-stepwise selection by Akaike information criterion (AIC). Finally, the analysis used the statistically significant variables derived during the stepwise selection as independent variables. The list of these variables is as follows:

- $\quad$ Air temperature: The averages of the daily average temperatures $\left({ }^{\circ} \mathrm{C}\right)$ of the two-week period before the given trapping day defined the values of the variable (it was necessary to use two-week periods in the calculations because larval extrusion takes 8-14 days);

- The gradient of the ground near the trapping site: As continuous variable, it contained the gradient of the slope of the ground surface expressed in degrees;

- The distance of the trapping site from running waters: A variable value of 1 indicated running water within $1000 \mathrm{~m}$; a variable value of 0 indicated running water beyond $1000 \mathrm{~m}$ (the maximum distance that a mosquito may optimally be able to fly);

- The distance of the trapping site from standing waters: A variable value of 1 indicated standing water within $1000 \mathrm{~m}$; a variable value of 0 indicated standing water beyond $1000 \mathrm{~m}$; 
- The built-up density of the area of the trapping site: built-up density of $80 \%$ or over (S.L.: $\geq 80 \%$ ); built-up density between $30 \%$ and $80 \%$ (S.L.: $30-80 \%$ ); built-up density of $30 \%$ or less (S.L.: $\leq 30 \%$ ).

In the course of hypothesis test, the following null hypotheses were made: (1) the distance of the trapping site from running waters does not influence the number of mosquitoes; (2) the extent of the built-up density of the urban areas does not affect the number of mosquitoes. thus, no difference was expected to be found in the average number of the mosquitoes captured in areas of different built-up density. When examining the average temperature, the initial assumption was that a given average air temperature provides advantageous circumstances for the reproduction of mosquitoes. This means the emergence of the favorable average temperature results in the rise of the number of captured mosquitoes in the traps. However, no such preferred temperature value could be defined on the basis of scientific literature. Therefore, in the course of the analysis the observations were repeatedly divided into two sub-samples according to the average temperature values. This method contributed to answering the question of whether the number of mosquitoes would fall if the average temperature was lower than a given temperature.

In the testing of the hypotheses, the Welch two-sample t-test was applied due to the large sample size. Normality was tested using both the Jarque-Bera test and Shapiro-Wilk test. Since based on the results of the normality tests $(p \leq 0)$, the normality could not be assumed, and the Kruskal-Wallis non-parametric rank-sum test was also run. However, in the course of making up the sub-samples, in some cases the number of elements in a sub-sample was low or normality could not be assumed. In these cases, the Wilcoxon rank-sum test was used.

Considering the fact that at the examination of the impacts related to the built-up density of the urban area the grouping variable divided the observations into three groups, at the comparison of the average of each group, one-way analysis of variance (ANOVA) and the Welch one-way test was applied.

In addition to hypothesis testing, the ordinary least squares regression method was also applied.

The analysis of the geographical information took place with the use of QGIS v3.4 software and the exploratory analysis in $\mathrm{R} \mathrm{v3.6.3.}$

\section{Results}

Data analysis showed meaningful and relevant results regarding both the hypothesis tests and the exploratory analysis. Accordingly, it can be stated that the research program has achieved its objectives: first, we succeeded in showing that there are statistically significant differences regarding the average number of mosquitoes in the different areas of the city. On the other hand, the features of the urban environment that play a role in the changes in the average number of mosquitoes in the different areas of the city were successfully identified. On that basis, areas of the city in which mosquito control activity should be focused could be defined. At the same time, the areas of the city where interventions of lower intensity may be necessary compared to the intensity of the earlier mosquito control measures could also be defined. All these results can contribute to the planning and implementation of a sustainable and resource-efficient city mosquito control activity.

As regards the hypothesis investigations, the results of the t-test showed significant $(p \leq 0.01)$ differences in the sub-samples at the study of the relationship between the distance of trapping sites from running waters and the number of mosquitoes; therefore, the null hypothesis was discarded. The results are shown in Figure 2. In the case of the boxplot, the symbol $\mathrm{X}$ represents the mean value; the thick line inside the rectangle represents the median, the bottom of the rectangle represents the lower quartile while the top represents the upper quartile. The width of the rectangle represents the middle $50 \%$ of data. 


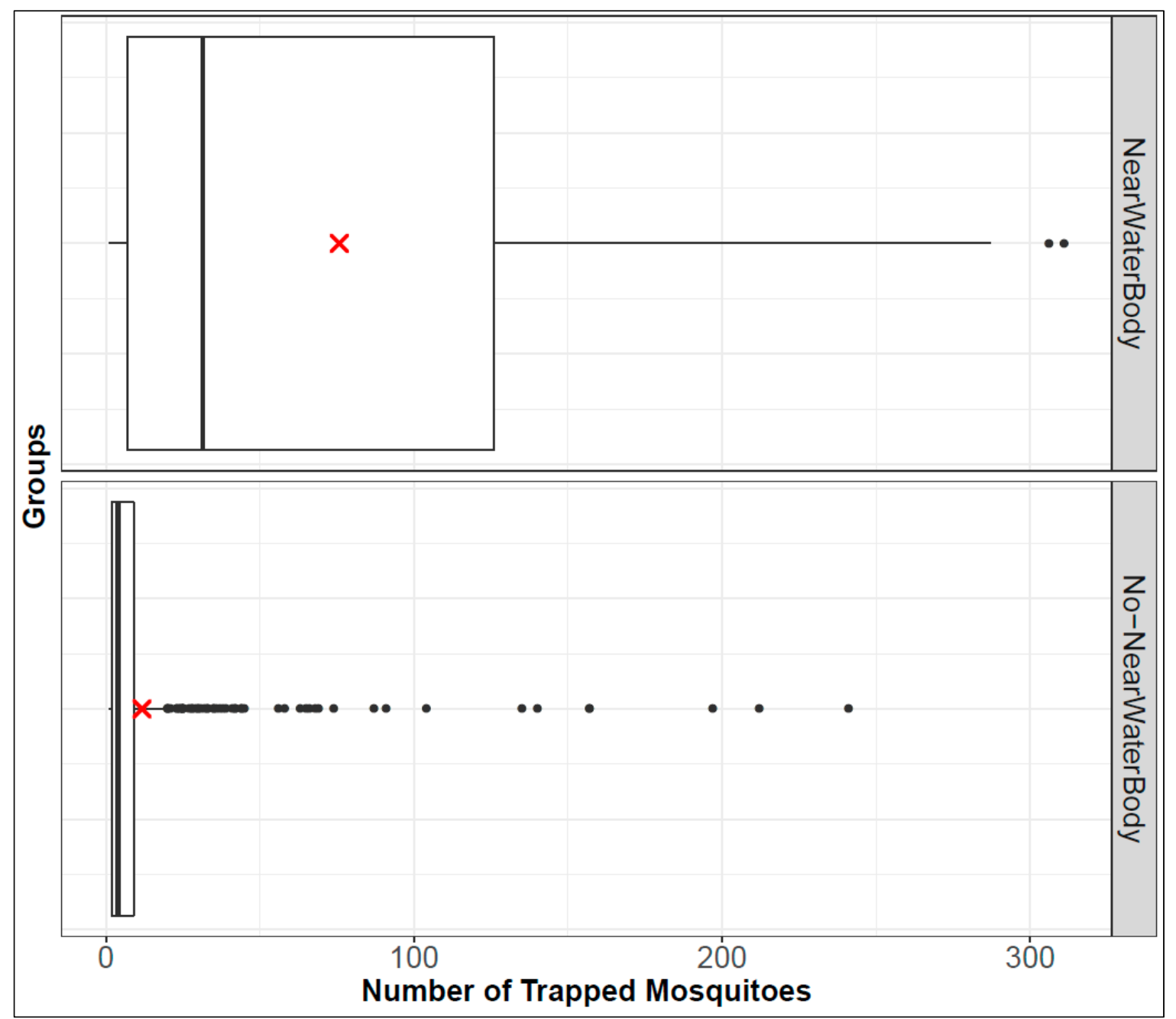

Figure 2. The relationship between the average number of mosquitoes and standing water within $1000 \mathrm{~m}$.

It can consequently be stated that if standing water is to be found within $1000 \mathrm{~m}$ radius of the trapping site then the average number of mosquitoes is significantly higher than if there is no standing water within that distance.

Regarding the built-up density of the urban areas and the average number of mosquitoes, the hypothesis that the group averages are identical can be discarded, as significant $(p \leq 0.01)$ difference was found between the average number of the captured mosquitoes in the areas of different built-up density. The results are shown in Figure 3. In the case of the boxplot, the symbol X represents the mean value; the thick line inside the rectangle represents the median, the bottom of the rectangle represents lower quartile while the top represents the upper quartile. The width of the rectangle represents the middle $50 \%$ of data.

Considering the differences in the average number of mosquitoes in the urban areas with different built-up density, it can be stated that the average number of mosquitoes is significantly higher in the areas of $30 \%$ or less built-up density compared to the other urban areas.

When the relationship between the daily average temperature and the average number of mosquitoes was examined, the sub-sampling based on the average temperature values showed significant $(p \leq 0.05)$ differences in 55 cases altogether. Figure 4 shows the results in a histogram.

To conclude the results of the hypothesis tests, it can be stated that the distance of the area from running water, the built-up density and the average temperature have a causal impact on the average number of mosquitoes of an urban area. Each of these factors showed direct impact, and the impact intensified with the combination of the three factors. 
The goal of the exploratory analysis was to quantify the impact of each factor on the number of mosquitoes. The range of the analyzed variables was not limited to the factors examined in the hypothesis tests, but another variable referring to the gradient of the ground was added. The results of the analysis are listed in Table 1.

Table 1. Quantified results of the effects of the factors influencing the number of mosquitoes.

\begin{tabular}{cccccc}
\hline & Estimate & Std. Error & Statistic & $p$ Value & \\
\hline (Intercept) & -36.435 & 14.925 & -2.441 & $=0.015$ & $* *$ \\
Urban sealing layer: $\leq 30 \%$ & 22.231 & 5.064 & 4.39 & $\leq 0.01$ & $* * *$ \\
Urban sealing layer: $30-80 \%$ & 15.642 & 4.131 & 3.787 & $\leq 0.01$ & $* * *$ \\
Slope & -2.04 & 0.645 & -3.16 & 0.002 & $* * *$ \\
NearWaterBody & 53.303 & 12.81 & 4.161 & $\leq 0.01$ & $* * *$ \\
AvTemp & 2.042 & 0.68 & 3.002 & $=0.003$ & $* * *$ \\
Residual standard error & $39.29(\mathrm{df:} 435)$ & & & & \\
Multiple R-squared & 0.2825 & & & & \\
Adjusted R-squared & 0.2742 & & & & \\
F-statistic & $34.25(\mathrm{df1}: 5, \mathrm{df2}: 435)$ & & & & \\
$p$-value & $<2.2 \times 10^{-16}$ & & & &
\end{tabular}

Note: ${ }^{* *} p \leq 0.05 ;{ }^{* * *} p \leq 0.01$. Standard errors robust to heteroscedasticity.

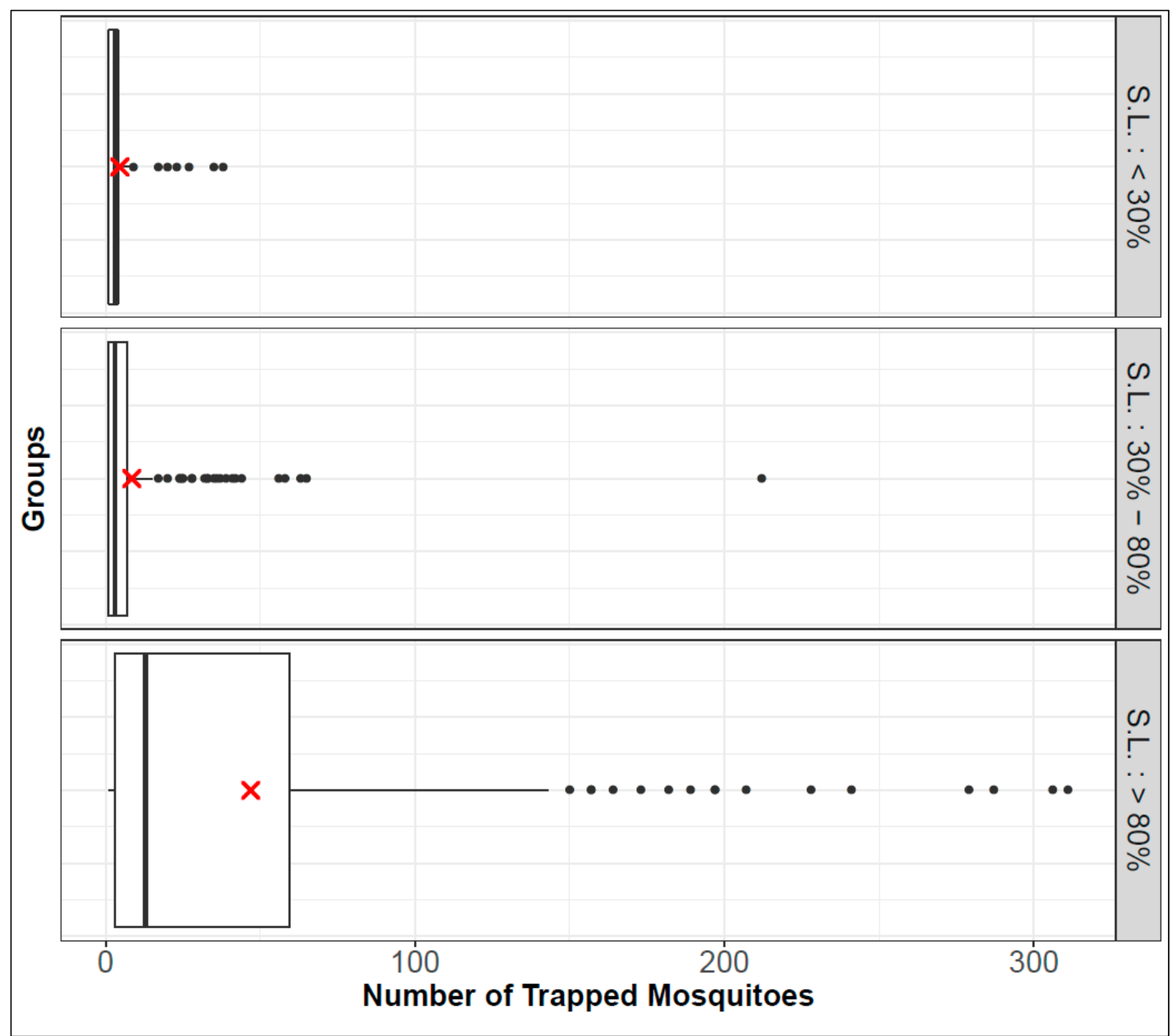

Figure 3. The relationship between the average number of mosquitoes and the built-up density. 


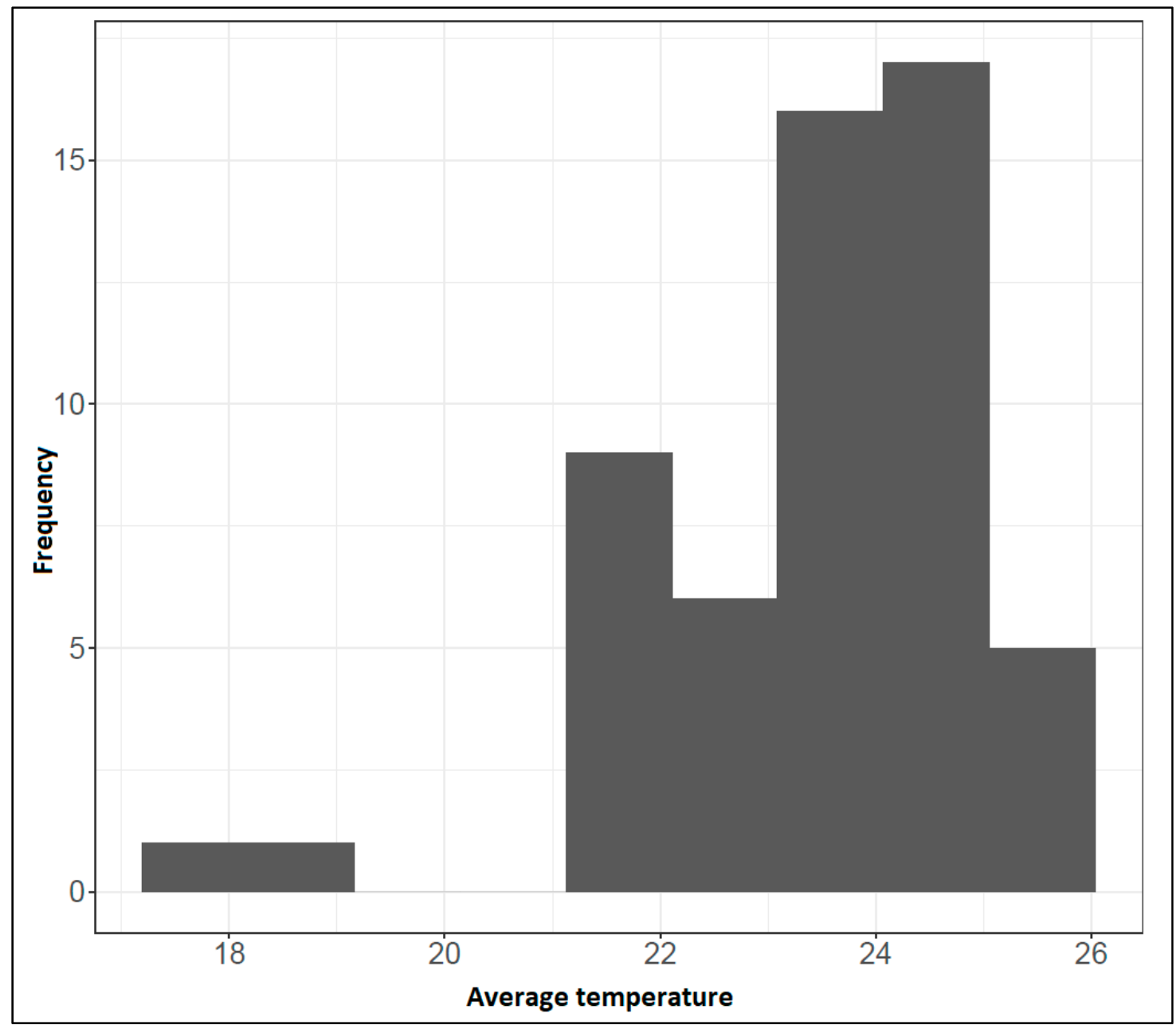

Figure 4. Average temperatures that statistically significantly influence the number of mosquitoes.

The regression model showed a significant $(p \leq 0.05)$ result in each variable examined. Thereby, the results of the hypothesis tests were confirmed. Furthermore, other observations were possible for the three factors examined. Standing water within or beyond $1000 \mathrm{~m}$ had the most significant (53.3) impact on the changes of the number of mosquitoes. The impact of built-up density of $\leq 30 \%$ was also significant; however, its effect was only half as strong (22.2) when compared to the impact of the proximity of standing water. The effect increasing the number of mosquitoes (2.04) related to each Celsius grade of the increase of the average temperature regarding the interval between 21 and 26 Celsius can significantly enhance the growth of the numbers of mosquitoes. Finally, according to the impact related to the gradient of the ground, fewer mosquitoes $(-2.04)$ are to be expected with each grade in the areas of higher slope gradient than in those of steeper gradient. Altogether, all these data can significantly contribute to the targeted selection of the sites of larviciding and also to the planning of the intensity of the process related to average temperature.

Concluding the results of the analysis, it can be stated that on the basis of the data of SMM, some features that have a causal impact on the average number of mosquitoes in a given urban environment were successfully identified. Moreover, the differences between the intensity of the effects of the different factors could also be shown.

With the application of the key results of the analysis described above, a mosquito map supporting the planning of the local mosquito control focusing on larviciding (Figure 5) was developed. 


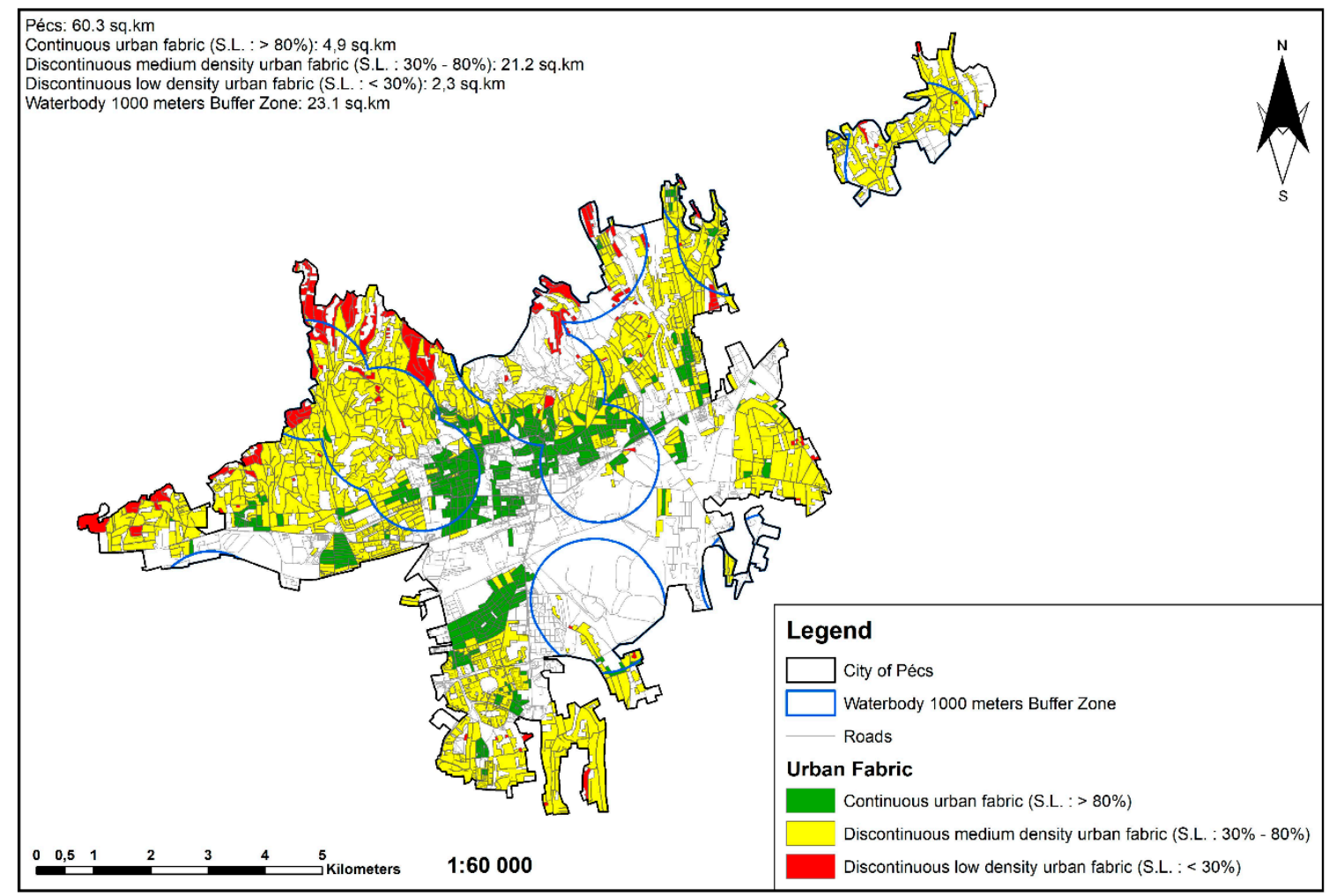

Figure 5. Mosquito map supporting the planning of the local mosquito control tasks.

\section{Discussion}

Implementation of planned and targeted prevention can significantly increase the effectiveness and efficiency of interventions in urban health-related concerns [27]. Targeted and planned intervention should, however, take place on the basis of appropriate data related to mosquito breeding areas [28-30].

The mosquito monitoring and control initiatives vary among settings, purpose and available resources. However, several examples underpin the rationale of these efforts. One such example is the mosquito maps of the European Centre for Disease Prevention and Control [31]. Data regarding the mosquito population, its faunistic features and the natural and built environmental characteristics of their breeding area are of vital importance for the planning of mosquito control measures in an urban environment. In the case of Pécs, with the help of the SMM data, mosquito control activities in the different parts of the city can be well defined and applied in a concentrated manner. The effectiveness of the achieved mosquito control can be assessed on the basis of the data too. As a result of this research, the development of a mosquito control approach has been started in the city of Pécs. This process can provide an example for other Hungarian cities. This first step is relevant because all of the neighboring countries of Hungary have already established some mosquito monitoring systems, mainly on national or at least regional levels [32-37]. With the monitoring system of Pécs, Hungary may start to catch up with the European trend.

Using the mosquito map, the identification of urban areas for mosquito control may become data-driven for city management. In the case of Pécs, these areas can be the parts of the city having a built-up density of $\leq 30 \%$ and the ones situated within $1000 \mathrm{~m}$ of standing waters. Based on these two criteria, intensive larviciding is advised to be applied in about $42.1 \%$ of the total residential areas of the city. Therefore, mosquito control of lower intensity could also be sufficient in the remaining $57.9 \%$ of the city area. This resource reallocation based on planning can boost the efficiency of the control and lead to a positive change towards sustainability in terms of reduced pressure on the environment and reduced expenses of protection. 
The Pécs mosquito monitoring initiative may increase the effectiveness of mosquito control interventions in the urban environment, also taking the criteria of sustainable environmental use and resources management into account. In addition, the results can also help to complete the tasks arising from regulation change in Hungary relating to the use of mosquito insecticides. Larviciding with biological agents of selective effect complying with the new regulations can become more efficient together with the developed mosquito map than chemical protection previously used for adulticiding. Thereby, environmental exposure can also be much lower [38]. Moreover, the risks of mosquito-borne diseases and also the inconveniences caused by biting mosquitoes can be continuously kept at a low level throughout the mosquito season with timely interventions. These can be defined with the help of the regular analysis of the temperature forecasts. Accordingly, the ex post facto measures initiated by the increased number of mosquitoes can be replaced by preventive and proactive planning and intervention in mosquito control.

The mosquito map may also become a useful tool for the involvement of the public in mosquito control activities. Using the mosquito map in the areas with high numbers of mosquitoes, the members of the local community can be reached through targeted communication. The aim of this communication is to emphasize the importance of mosquito control and give information about the high-risk periods on the basis of the forecasts. On the other hand, people living in higher mosquito-risk areas could be invited to demonstration activities and workshops where they can get informed about the mosquito control possibilities of private households. Thereby, the communities concerned can actively take part in the mosquito control activities. This contribution can significantly increase the efficiency of the interventions [39]. Accordingly, the combined effects of community activities and city maintenance solutions can offer the possibility to implement an effective, efficient as well as sustainable mosquito control in the coming period in Pécs.

\section{Conclusions}

Assessing and understanding the characteristics of a given aspect of an urban health-related concern may serve as a vehicle to address the issue. Based on the results of the research project, our research group developed a mosquito map that could contribute to planning focused and targeted mosquito control in a given urban environment. The methods used and solutions offered may also be suitable for risk assessment of vector-borne diseases as well. Our next step is to build a comprehensive larviciding approach that incorporates both the use of biological agents and community resources and can be suitable for use in a wide variety of urban environments.

Nevertheless, with the use of SMM and the method of risk assessment with mosquito maps based on SMM, the city of Pécs has taken a substantial step towards the shaping a health-enabling urban environment in a sustainable way.

Supplementary Materials: The following are available online at http://www.mdpi.com/2071-1050/12/12/5013/s1.

Author Contributions: Conceptualization, T.K. and J.G.; methodology, formal analysis, R.B. and G.M.; investigation, C.L. and T.Z.; data curation, R.B., T.Z. and G.M.; writing-original draft preparation, T.K., C.L., R.B., G.M. and J.G.; visualization, R.B. and G.M.; supervision, J.G.; project administration, T.Z. All authors have read and agreed to the published version of the manuscript.

Funding: This research received no external funding.

Acknowledgments: The research project is conducted at the University of Pécs, Hungary, within the framework of the Biomedical Engineering Project of the Thematic Excellence Programme 2019 (TUDFO/51757-1/2019-ITM).

Conflicts of Interest: The authors declare no conflict of interest.

\section{References}

1. World Urbanization Prospects 2018. Highlights. Department of Economic and Social Affairs, Population Division, United Nations, New York, 2019. Available online: https:/population.un.org/wup/Publications/ Files/WUP2018-Report.pdf (accessed on 20 March 2020). 
2. Schwab, G.L.; Moysés, S.J.; França, B.H.S.; Werneck, R.I.; Frank, E.; Moysés, S.J. Healthy cities fighting against chronic conditions. Environ. Pr. 2015, 17, 16-24. [CrossRef]

3. Van De Poel, E.; O'Donnell, O.; Van Doorslaer, E. Is there a health penalty of China's rapid urbanization? Health Econ. 2011, 21, 367-385. [CrossRef]

4. Wilcox, B.A.; Gubler, D.J.; Pizer, H. Urbanization and the social ecology of emerging infectious diseases. In The Social Ecology of Infectious Diseases; Kenneth, H., Mayer, H.F.P., Eds.; Academic Press: Cambridge, MA, USA, 2008; pp. 113-137. [CrossRef]

5. Climate Change and Cities. Second Assessment Report on Climate Change and Cities (ARC3.2) Urban Climate Change Research Network, Center for Climate Systems Research, Earth Institute, Columbia University, USA, 2018. Available online: http://uccrn.org/files/2019/09/ARC3.2-PDF-Chapter-10-Urban-Health-wecompress. com_.pdf (accessed on 20 March 2020).

6. Transforming Our World: The 2030 Agenda for Sustainable Development. United Nations. 2014. A/RES/70/1. Available online: https://sustainabledevelopment.un.org/content/documents/21252030\%20Agenda\%20for\% 20Sustainable\%20Development\%20web.pdf (accessed on 10 February 2020).

7. Hidden Cities: Unmasking and Overcoming Health Inequities in Urban Settings. World Health Organization, The WHO Centre for Health Development, Kobe, and United Nations Human Settlements Programme (UN-HABITAT), 2010. Available online: https://apps.who.int/iris/bitstream/handle/10665/44439/ 9789241548038_eng.pdf?sequence=1\&isAllowed=y (accessed on 10 February 2020).

8. Neiderud, C.-J. How urbanization affects the epidemiology of emerging infectious diseases. Infect. Ecol. Epidemiol. 2015, 5, 27060. [CrossRef] [PubMed]

9. Eder, M.; Cortes, F.; De Siqueira-Filha, N.T.; De França, G.V.A.; DeGroote, S.; Braga, M.C.; Ridde, V.; Martelli, C.M.T. Scoping review on vector-borne diseases in urban areas: Transmission dynamics, vectorial capacity and co-infection. Infect. Dis. Poverty 2018, 7, 90. [CrossRef]

10. Alonso, P.; Engels, D.; Reeder, J. Global Vector Control Response 2017-2030; World Health Organization: Geneva, Schwitzerland, 2017; Available online: https:/apps.who.int/iris/bitstream/handle/10665/259205/ 9789241512978-eng.pdf?sequence=1 (accessed on 20 March 2020).

11. Semenza, J.; Suk, J.E. Vector-borne diseases and climate change: A European perspective. FEMS Microbiol. Lett. 2017, 365, 2. [CrossRef]

12. Manual on Prevention of Establishment and Control of Mosquitoes of Public Health Importance in the WHO European Region. WHO Regional Office for Europe, Copenhagen, Denmak, 2019. Available online: http://www.euro.who.int/_data/assets/pdf_file/0004/392998/mosquito-manual-eng.pdf?ua=1 (accessed on 20 March 2020).

13. Van den Berg, H.; Schaffner, F. Training Curriculum on Invasive Mosquitoes and (re-)Emerging Vector-Borne Diseases in the WHO European Region; Copenhagen: WHO Regional Office for Europe: Copenhagen, Denmark, 2016; Available online: http://www.euro.who.int/_data/assets/pdf_file/0005/329495/Training-curriculuminvasive-mosquitoes.pdf?ua=1 (accessed on 20 March 2020).

14. Guidelines for the Control of Mosquitoes of Public Health Importance in Europe. European Mosquito Control Association, 2013. Available online: https://www.emca-online.eu/emca/who-guidelines (accessed on 10 February 2020).

15. A Szúnyogállomány Monitorozásának és Célzott Gyérítésének Járványügyi Fontossága. MTA (The Epidemiological Relevance of Monitoring and Targeted Abatement of Mosquitoes. Hungarian Academy of Sciences), 2018. Available online: https://mta.hu/tudomany_hirei/a-szunyogallomany-monitorozasanak-escelzott-gyeritesenek-jarvanyugyi-fontossaga-a-magyar-tudomanyos-akademia-felhivasa-es-megoldasijavaslata-a-donteshozok-szamara-2018-109136 (accessed on 10 February 2020).

16. Tóth, S.; Kenyeres, Z. Revised checklist and distribution maps of mosquitoes (Diptera, Culicidae) of Hungary. European Mosquito Bulletin. J. Eur. Mosq. Control Assoc. 2012, 30, 30-65. Available online: http://e-m-b.org/sites/e-m-b.org/files/EMB\%2830\%2930-65.pdf (accessed on 10 February 2020).

17. Sáringer-Kenyeres, M.; Kenyeres, Z.; Bakonyi, T. Biting mosquito data from the Lake Balaton region for the surveillance of West Nile virus infection. J. Eur. Mosq. Control Assoc. 2019, 37, 34-40. Available online: http://e-m-b.org/sites/e-m-b.org/files/JEMCA\%2037\%20p\%2034-40.pdf (accessed on 10 February 2020).

18. Kurucz, K.; Kiss, V.; Zana, B.; Schmieder, V.; Kepner, A.; Jakab, F.; Kemenesi, G. Emergence of Aedes koreicus (Diptera: Culicidae) in an urban area, Hungary, 2016. Parasitol. Res. 2016, 115, 4687-4689. [CrossRef] 
19. European Centre for Disease Prevention and Control Agency. Aedes Koreicus_Factsheet for Experts; Centre for Disease Prevention and Control and European Food Safety Authority: Stockholm, Sweden, 2014; Available online: https://www.ecdc.europa.eu/en/disease-vectors/facts/mosquito-factsheets/aedes-koreicus (accessed on 10 February 2020).

20. Aedes Koreicus - Current Known Distribution: July 2019. European Centre for Disease Prevention and Control and European Food Safety Authority, Stockholm. Mosquito Maps. Available online: https://ecdc.europa.eu/en/ disease-vectors/surveillance-and-disease-data/mosquito-maps (accessed on 10 February 2020).

21. Baldacchino, F.A.; Caputo, B.; Chandre, F.; Drago, A.; Della Torre, A.; Montarsi, F.; Rizzoli, A. Control methods against invasiveAedesmosquitoes in Europe: A review. Pest Manag. Sci. 2015, 71, 1471-1485. [CrossRef]

22. Bonds, J.A.S. Ultra-low-volume space sprays in mosquito control: A critical review. Med. Vet. Èntomol. 2012, 26, 121-130. [CrossRef]

23. Smeraldo, S.; Bosso, L.; Fraissinet, M.; Bordignon, L.; Brunelli, M.; Ancillotto, L.; Russo, D. Modelling risks posed by wind turbines and power lines to soaring birds: The black stork (Ciconia nigra) in Italy as a case study. Biodivers Conserv. 2020, 29, 1959-1976. [CrossRef]

24. Şandric, I.; Satmari, A.; Zaharia, C.; Petrovici, M.; Cimpean, M.; Battes, K.P.; David, D.-C.; Pacioglu, O.; Weiperth, A.; Gál, B.; et al. Integrating catchment land cover data to remotely assess freshwater quality: A step forward in heterogeneity analysis of river networks. Aquat. Sci. 2019, 81, 26. [CrossRef]

25. Mentzafou, A.; Varlas, G.; Dimitriou, E.; Papadopoulos, A.; Pytharoulis, I.; Katsafados, P. Modeling the effects of anthropogenic land cover changes to the main hydrometeorological factors in a regional watershed, Central Greece. Climate 2019, 7, 129. [CrossRef]

26. Micek, O.; Feranec, J.; Stych, P. Land use/land cover data of the urban atlas and the cadastre of real estate: An evaluation study in the Prague Metropolitan Region. Land 2020, 9, 153. [CrossRef]

27. Dora, C.; Mingle, J.; Fletcher, E. (Eds.) Health as the Pulse of the New Urban Agenda; United Nations Conference on Housing and Sustainable Urban Development: Quito, Ecuador, 2016; Available online: https://apps.who.int/iris/bitstream/handle/10665/250367/9789241511445-eng.pdf?sequence=1 (accessed on 10 February 2020).

28. Neteler, M.; Roiz, D.; Rocchini, D.; Castellani, C.; Rizzoli, A. Terra and Aqua satellites track tiger mosquito invasion: Modelling the potential distribution of Aedes albopictus in north-eastern Italy. Int. J. Health Geogr. 2011, 10, 49. [CrossRef] [PubMed]

29. Petrić, D.; Bellini, R.; Scholte, E.J.; Marrama, L.; Schaffner, C. Monitoring population and environmental parameters of invasive mosquito species in Europe. Parasites Vectors 2014, 7, 187. [CrossRef] [PubMed]

30. Asingizwe, D.; Murindahabi, M.M.; Koenraadt, C.J.M.; Poortvliet, P.M.; Van Vliet, A.; Ingabire, C.M.; Hakizimana, E.; Mutesa, L.; Takken, W.; Leeuwis, C.; et al. Co-designing a citizen science program for malaria control in Rwanda. Sustainability 2019, 11, 7012. [CrossRef]

31. European Centre for Disease Prevention and Control Mosquito Maps. Available online: https://www.ecdc. europa.eu/en/disease-vectors/surveillance-and-disease-data/mosquito-maps (accessed on 10 June 2020).

32. Kalan, K.; Buzan, V.; Ivovic, V. Distribution of two invasive mosquito species in Slovenia in 2013. Parasites Vectors 2014, 7, P9. [CrossRef]

33. Austrian Gnat Monitoring Programme by AEGES. Available online: https://www.ages.at/en/topics/agestopics/vector-borne-diseases/mosquito-monitoring/\# (accessed on 10 June 2020).

34. Marianna Dzidová, M.; Čabanová, V.; Stloukal, E.; Miterpáková, M. Mosquito fauna and risk of mosquito-borne diseases in the capital city Bratislava, Slovakia-The results of a preliminary monitoring. Folia Faunistica Slovaca 2016, 21, 245-250.

35. Petrović, T.; Sekler, M.; Petric, D.; Lazić, S.; Debeljak, Z.; Vidanovic, D.; Ćupina, A.I.; Lazić, G.; Lupulović, D.; Kolarević, M.; et al. Methodology and results of integrated WNV surveillance programmes in Serbia. PLoS ONE 2018, 13, e0195439. [CrossRef]

36. Croatian Institute of Public Health: National Monitoring of Invasive Mosquito Species. Available online: https://www.hzjz.hr/en/news/national-monitoring-of-invasive-mosquito-species/ (accessed on 10 June 2020).

37. Török, E.; Tomazatos, A.; Cadar, D.; Horváth, C.; Keresztes, L.; Jansen, S.; Becker, N.; Kaiser, A.; Popescu, O.; Schmidt-Chanasit, J.; et al. Pilot longitudinal mosquito surveillance study in the Danube Delta Biosphere Reserve and the first reports of Anopheles algeriensis Theobald, 1903 and Aedes hungaricus Mihályi, 1955 for Romania. Parasites Vectors 2016, 9, 196. [CrossRef] [PubMed] 
38. Huang, Y.-J.S.; Higgs, S.; VanLandingham, D.L. Biological control strategies for mosquito vectors of Arboviruses. Insects 2017, 8, 21. [CrossRef] [PubMed]

39. Arostegui, J.; Ledogar, R.J.; Coloma, J.; Hernández-Alvarez, C.; Suazo-Laguna, H.; Cárcamo, A.; Reyes, R.M.; Belli, A.; Andersson, N.; Harris, E.; et al. The Camino Verde intervention in Nicaragua, 2004-2012. BMC Public Health 2017, 17, 406. [CrossRef] [PubMed] 